\title{
Abundance and Borrelia burgdorferi-infection Prevalence of Nymphal Ixodes scapularis Ticks along Forest-Field Edges
}

\author{
Valerie Horobik, ${ }^{1}$ Felicia Keesing, ${ }^{2,3}$ and Richard S. Ostfeld ${ }^{3}$ \\ ${ }^{1}$ Institute of Environmental Science, Miami University, Boyd Hall, Oxford, OH 45056 \\ ${ }^{2}$ Biology Department, Bard College, Annandale-on-Hudson, New York, NY 12504 \\ ${ }^{3}$ Institute of Ecosystem Studies, 65 Sharon Turnpike, Millbrook, NY 12545
}

\begin{abstract}
More than 19,000 human cases of Lyme disease (LD) are reported each year in the United States. Lyme disease cases occur when humans are exposed to the bacterium Borrelia burgdorferi through the bite of an infected ixodid tick. The probability of human exposure to infected ticks results from a combination of human behaviors and entomological risk. Human behaviors include use of tick habitats, use of protective clothing, and grooming for tick removal. Entomological risks include the density of ticks in a habitat and the proportion of these that are infected with $B$. burgdorferi. Recent studies have suggested that humans are at higher risk of exposure to B. burgdorferi near edges between forests and herbaceous communities, including lawns and old fields, but whether this increased risk is a function of human behaviors, entomological risk, or both, is unknown. We assessed entomological risk across forest-old field edges in Dutchess County, NY. Densities of ticks and of infected ticks were considerably higher within forests than at forest-field edges, and were lowest within fields. Thus, edges between forests and fields do not pose a higher entomological risk than do the forests themselves, although risk at the edge is higher than in herbaceous habitat. Landscapes with abundant edges between forested and herbaceous habitat, and roughly even proportions of both, might attract both heavy human use and pose moderately high entomological risk, and thus could be targeted for mitigation. We suggest that determining appropriate methods for reducing human exposure to LD requires differentiating entomological risk from human behaviors.
\end{abstract}

Key words: blacklegged tick, Borrelia burgdorferi, Ixodes scapularis, landscape epidemiology, Lyme disease, tick ecology

\section{INTRODUCTION}

Lyme disease is the most common vector-borne disease in the United States with $\geq 19,000$ human cases reported annually in recent years (CDC, 2004). Although $>90 \%$ of Lyme disease cases are reported in 10 states, 8 of which are

Correspondence to: Richard S. Ostfeld, e-mail: Rostfeld@ecostudies.org in the Northeast and mid-Atlantic regions, cases have been reported in 49 states and the District of Columbia (Orloski et al., 2000). The causative agent is a spirochete bacterium Borrelia burgdorferi, which is transmitted by the bite of ixodid ticks, predominantly Ixodes scapularis in the eastern and central United States. Because diagnosis and treatment remain problematic (e.g., Dinser et al., 2005) and no vaccine is currently available, prevention of encounters be- 
tween humans and infected ticks is a key part of the public health arsenal against this increasingly widespread disease.

The probability of encounter between humans and infected ticks is a function of both human behavior and entomological risk. Important human behaviors include use of different terrestrial habitats, use of protective clothing and repellents, and auto- or allogrooming to remove ticks. Key aspects of entomological risk are the abundance and B. burgdorferi-infection prevalence of nymphal ticks, as most cases of Lyme disease are a result of the bite of this life stage (Piesman et al., 1987; Barbour and Fish, 1993).

Several recent studies have reported that human risk or incidence rate of Lyme disease is associated with edges between forest and herbaceous plant communities, including lawns and old fields (Das et al., 2002; Dister et al., 1997; Frank et al., 1998; Jackson et al., 2006). For example, in a study from Maryland, Jackson et al. (2006) found that human incidence rate of Lyme disease was positively correlated with the percentage of land cover edges that consisted of forest-herbaceous habitat adjacency. Jackson et al. (2006) postulated that Lyme disease incidence could be reduced by landscape designs that avoid a high degree of interspersion between forest and herbaceous fields.

The positive association between forest-herbaceous edges and Lyme disease incidence could result from either heavy human use of these edges, elevated entomological risk at edges compared to other landscape elements, or both. Whether human behavior or tick abundance and infection prevalence is predominantly responsible for high incidence associated with edges is likely to be important in informing prevention strategies. In this study, we assessed whether edges between forests and herbaceous fields present higher entomological risk than do other landscape elements. Such edges are quite common elements in the post-agricultural landscapes of the northeastern U.S.A. where Lyme disease is endemic.

\section{Methods}

We examined entomological risk of human exposure to Lyme disease in three landscape elements-deciduous forest, herbaceous fields, and edges between forest and field-in the summers of 2001 and 2002. The density of infected nymphs (DIN) is regarded as the primary measure of entomological risk (Mather, 1993; Ostfeld and Keesing, 2000). DIN, in turn, is the product of the total density of nymphs (DON) and the nymphal infection prevalence (NIP). DON is a function of both abiotic factors affecting tick abundance and the availability of larval blood-meal hosts (Van Buskirk and Ostfeld, 1998). NIP is determined by the local abundance of blood-meal hosts with high infectivity, or reservoir competence. All study sites were on or near the grounds of the Institute of Ecosystem Studies $\left(41^{\circ} 50^{\prime} \mathrm{N}, 73^{\circ} 45^{\prime} \mathrm{W}\right)$, located in Dutchess County, NY, a county with one of the highest incidence rates of Lyme disease in the United States (Orloski et al., 2000).

Each year, six plots were chosen along forest-old field edges, and, in each plot, transects were established running parallel to the forest edge. During 2001, 80-m long, 2-m wide transects were established, centered at $4 \mathrm{~m}$ within the forest and 1, 11, 21, and $34 \mathrm{~m}$ into old fields. In 2002, 50-m long, $1-\mathrm{m}$ wide transects were established at $10-\mathrm{m}$ intervals from the forest edge to $50 \mathrm{~m}$ within the forests. Locations $50 \mathrm{~m}$ within the forests represent forest "interior" in terms of air temperature, daily temperature stability, relative humidity, soil moisture, and light intensity (Cadenasso et al., 1997; Murcia, 1995; Williams-Linera, 1990). Due to physical constraints, the sixth forest plot consisted of only four $50-\mathrm{m}$ transects parallel to the forest edge at $10-\mathrm{m}$ intervals from the edge to $30 \mathrm{~m}$ within the forest. No portion of the most interior transect of the plots lay closer to another forest edge than the one on which the plot was located. Following set-up, the plots were left idle for 1 week to allow for recovery from any tick or mammal disturbance caused during the setting up of transects.

Between 1000 and 1600 hours during the nymphal activity peak (June 21-July 14), nymphal density measurements were taken along each transect. In 2001, a single measurement was taken; in 2002, two measurements were taken and averaged to determine density of nymphs (DON) for each transect. These measurements were made via drag sampling, a method shown to be reliable and effective (Falco and Fish, 1992), in which a $1 \mathrm{~m}^{2}$ white corduroy cloth was pulled along each transect. The cloth was weighted on one edge to keep it as close to the ground as possible, and, every $10 \mathrm{~m}$, all nymphal $I$. scapularis on the cloth or the investigator's clothing were counted, removed, and maintained alive for later nymphal infection prevalence (NIP) analysis.

Additional nymphs were collected throughout late July of each year to increase sample size for determining infection prevalence. A minimum of 20 ticks per transect were collected from the forest transects in 2002; however, due to problems collecting an acceptable number of ticks 
from the two transects farthest into the old fields, the five distance categories used for DON measurements within the fields were combined into four categories for NIP analysis. Thus, in 2001, the four distance categories for which NIP was examined were forest $(-4 \mathrm{~m})$, edge $(1 \mathrm{~m}), 11 \mathrm{~m}$, and $>21 \mathrm{~m}$ into the field. Also due to the low numbers of ticks within old fields, in 2001, nymphs from the same distance category were pooled across sites to have a sufficient number of nymphs from each distance for determining accurate NIP.

Collected nymphs were washed once in $70 \%$ ethanol and twice in deionized water before being individually suspended in phosphate-buffered saline (PBS) solution in an Eppendorf tube. Each tick was crushed until gut contents were released. After mixing, portions of this solution for each tick were placed in 3 wells of a 15-well microscope slide. After being set in cold acetone, fluorescent rabbit anti-Borrelia conjugate was added to each well and the slides were incubated at $37^{\circ} \mathrm{C}$ for 45 minutes. They were then washed in PBS and water, dried, and mounted in fluorescent-antibody mounting medium. Wells were examined for spirochetes under a fluorescent microscope at $400 \times$ magnification, with each tick being classified as positive or negative for the presence of B. burgdorferi. If a tick was not immediately identified as being positive for the bacteria, then all three wells for that tick were methodically scanned. In this manner, 20 nymphs from each transect (or distance category for the old field portion of the study) were examined, with NIP expressed as the proportion of nymphs infected for each transect or distance. Following determination of NIP, the DON for each of the transects was multiplied by the NIP for that transect (or for that distance category in 2001) to determine density of infected nymphs (DIN).

Following collection of nymphs in 2002, between August 6-8, two microhabitat variables were measured along each transect: leaf litter depth and downed wood abundance. Leaf litter depth was measured every $10 \mathrm{~m}$ along each transect using a standard centimeter ruler, with the measurements averaged for each transect. To measure downed wood abundance, woody debris was classified into three size classes based on diameter: $3-10 \mathrm{~cm}, 10-50 \mathrm{~cm}$, and $>50 \mathrm{~cm}$. Wood of diameter $<3 \mathrm{~cm}$ was not classified nor was wood not lying on the ground. For each transect, the number of intersections with woody debris of each of these classes was recorded.

For the complete data set, we used an ANCOVA model to analyze the DON and DIN data. Site, year, and their interaction were entered as factors, while distance from edge was a linear covariate. In entering distances for the combined data set, the most negative numbers referred to distances farthest from the forest edge into the field, while the highest positive numbers were those farthest from the edge within the forest. In order to minimize right-skew in the data, the DON and DIN data were natural log transformed.

Because the combined analysis did not allow for comparisons of DON and DIN among specific distances, and due to the large degree of variation among years in DON and DIN, the data from each year (or each side of the forest edge) were also analyzed separately. For each of the years, regression analyses were performed to assess whether DON, NIP, and DIN were functions of distance from forest edge into either old fields or forest interiors. One-way ANOVA with multiple comparisons were used to identify which specific distance categories differed in terms of DON, NIP, or DIN. Additionally, regression analyses were used to investigate whether DON, NIP, and DIN were related to leaf litter depth or downed wood abundance within the forest.

\section{Results}

The ANCOVA model explained $71 \%$ of the variation in lnDON. Significant year $\left(F_{1,51}=6.07, P=0.017\right)$, site $\left(F_{9,51}\right.$ $=6.16, P<0.0001)$, and distance $\left(F_{1,51}=27.33, P<0.0001\right)$ effects were noted, with the estimated effect of distance on $\operatorname{lnDON}$ being $\beta=0.015$ ( $\mathrm{SE}=0.003$ ) (where $\beta$ is the increase in $\operatorname{lnDON}$ or $\operatorname{lnDIN}$ for each unit increase in distance from the field into the forest). The same model explained $56 \%$ of the variation in $\operatorname{lnDIN}$, with significant site $\left(F_{9,51}=3.45, P=0.002\right)$ and distance $\left(F_{1,51}=13.84\right.$, $P=0.0005)$ effects. The effect of distance on $\operatorname{lnDIN}$ was estimated to be $\beta=0.007$ ( $\mathrm{SE}=0.002)$.

Total density of nymphs (DON) was a negative curvilinear function of distance from the forest edge into old fields (exponential decay curve, $R^{2}=0.35, P=0.0005$, $n=30$ ) (Fig. 1). Significant differences in mean DON were found among distances $\left(F_{4,25}=4.14, P=0.01\right)$, with density of nymphs $4 \mathrm{~m}$ within the forest significantly higher than DON at 21 or $34 \mathrm{~m}$ into the field (Tukey's HSD test, $\alpha$ $=0.05$ ) (Table 1). On the forest side of the edge, mean DON ranged from $0.108 \pm 0.037$ to $0.260 \pm 0.091$ nymphs/ $\mathrm{m}^{2}$ (Table 2). DON was not a linear function of distance from forest edge into forest interior $\left(R^{2}=0.07, P=0.12, n\right.$ 


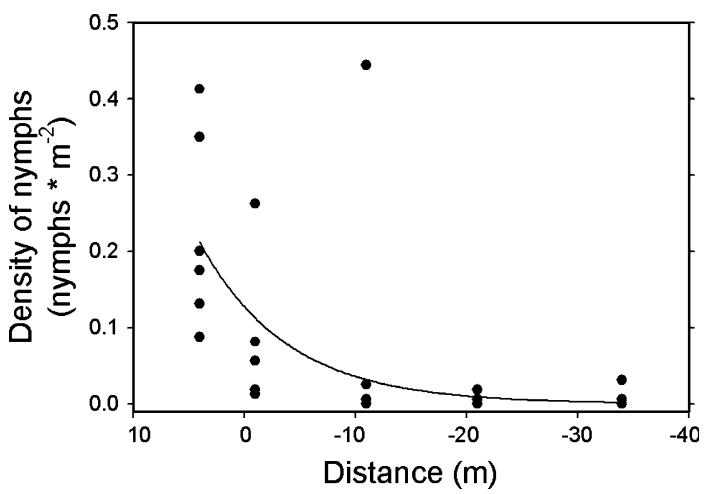

Figure 1. Total density of nymphs (DON) as a function of distance from forest edge into old fields, where forest distances are represented by positive values, the edge by zero, and field distances by negative values (exponential decay curve, $R^{2}=0.35, P=0.0005$, $N=30)$.

Table 1. Mean ( $\pm 1 \mathrm{SD}$ for DON and DIN) Values of Lyme Disease Risk Parameters for Each Distance from Forest Edge into Old Fields*

\begin{tabular}{llll}
\hline $\begin{array}{l}\text { Distance } \\
(\mathrm{m})\end{array}$ & $\begin{array}{l}\text { DON } \\
\left(\text { nymphs } / \mathrm{m}^{2}\right)\end{array}$ & $\begin{array}{l}\text { NIP } \\
\text { (proportion } \\
\text { infected) }\end{array}$ & $\begin{array}{l}\text { DIN } \\
\text { (infected } \\
\left.\text { nymphs } / \mathrm{m}^{2}\right)\end{array}$ \\
\hline 4 & $0.226 \pm 0.128^{\mathrm{a}}$ & 0.400 & $0.090 \pm 0.051^{\mathrm{a}}$ \\
-1 & $0.075 \pm 0.096^{\mathrm{a}, \mathrm{b}}$ & 0.235 & $0.018 \pm 0.023^{\mathrm{b}}$ \\
-11 & $0.083 \pm 0.177^{\mathrm{a}, \mathrm{b}}$ & 0.250 & $0.021 \pm 0.044^{\mathrm{b}}$ \\
-21 & $0.005 \pm 0.007^{\mathrm{b}}$ & 0.200 & $0.001 \pm 0.001^{\mathrm{b}}$ \\
-34 & $0.013 \pm 0.015^{\mathrm{b}}$ & 0.200 & $0.003 \pm 0.003^{\mathrm{b}}$ \\
\hline
\end{tabular}

DIN, density of infected nymphs; DON, density of nymphs; NIP, nymphal infection prevalence.

$\star$ The same letters are given to mean values that are not significantly different as determined by the Tukey's HSD multiple comparison test.

= 34). However, mean DON was significantly lower at the edge $(0-10 \mathrm{~m})$ compared to the interior $(20-50 \mathrm{~m})$ portions of the forest when the transects were grouped ( $\mathrm{t}_{\text {unequal }}$ $=-2.31, P=0.03, n=34$ ) (Fig. 2). Within the interior portion of the forest, mean nymphal density averaged $0.245 \pm 0.039$ nymphs $/ \mathrm{m}^{2}$, compared to $0.140 \pm 0.023$ nymphs $/ \mathrm{m}^{2}$ in the edge transects.

NIP was not significantly related to distance from the forest edge into old fields $\left(R^{2}=0.60, P=0.22, n=4\right)$, or into forest interior $\left(R^{2}=0.01, P=0.58, n=34\right)$. However, a notable negative trend was observed in 2001 between NIP and distance into old fields, with $40 \%$ of the nymphs captured in the forest being infected and between $20 \%$ and $25 \%$ of the nymphs captured at varying distances into the fields being
Table 2. Mean ( \pm 1 SE for DON and DIN and \pm 1 SD for NIP) Values of Lyme Disease Risk Parameters for Each Distance from Forest Edge into Interior

\begin{tabular}{llll}
\hline $\begin{array}{l}\text { Distance } \\
(\mathrm{m})\end{array}$ & $\begin{array}{l}\text { DON } \\
\left(\text { nymphs } / \mathrm{m}^{2}\right)\end{array}$ & $\begin{array}{l}\text { NIP } \\
\text { (proportion } \\
\text { infected) }\end{array}$ & $\begin{array}{l}\text { DIN } \\
\text { (infected } \\
\left.\text { nymphs } / \mathrm{m}^{2}\right)\end{array}$ \\
\hline 0 & $0.108 \pm 0.037$ & $0.317 \pm 0.068$ & $0.033 \pm 0.009$ \\
10 & $0.172 \pm 0.024$ & $0.350 \pm 0.032$ & $0.060 \pm 0.008$ \\
20 & $0.248 \pm 0.084$ & $0.333 \pm 0.098$ & $0.094 \pm 0.042$ \\
30 & $0.260 \pm 0.091$ & $0.342 \pm 0.116$ & $0.083 \pm 0.030$ \\
40 & $0.216 \pm 0.064$ & $0.230 \pm 0.110$ & $0.048 \pm 0.014$ \\
50 & $0.250 \pm 0.087$ & $0.340 \pm 0.204$ & $0.082 \pm 0.037$
\end{tabular}

DIN, density of infected nymphs; DON, density of nymphs; NIP, nymphal infection prevalence.

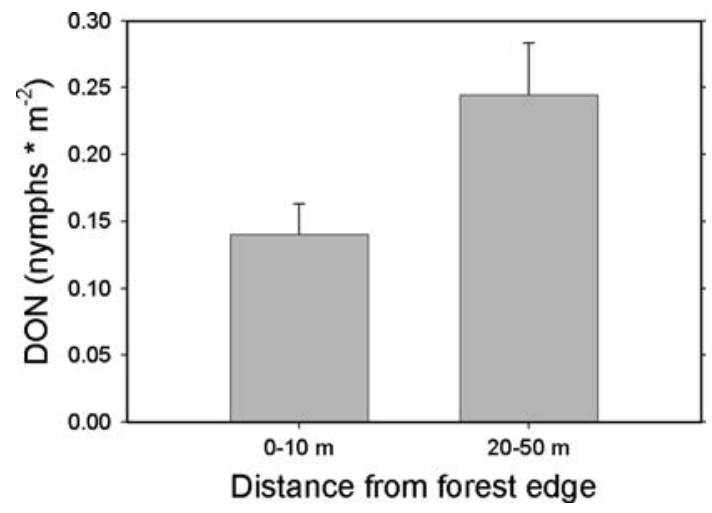

Figure 2. Mean density of nymphs $(\mathrm{DON}) \pm 1$ SE for forest edge $(0-10 \mathrm{~m})$ vs. forest interior $(20-50 \mathrm{~m})$ transects $\left(\mathrm{t}_{\text {unequal }}=-2.31, P=\right.$ $0.03, n=34)$.

infected (Table 1). Mean NIP from the various distances into the forest measured in 2002 ranged from $23 \pm 11 \%$ to $35 \pm 3.2 \%$ (Table 2), with no significant differences observed among the distances $\left(F_{5,28}=0.81, P=0.55\right)$.

DIN was a negative curvilinear function of distance into old fields (exponential decay curve, $R^{2}=0.53, P<0.0005$, $n=30$ ), being significantly higher $4 \mathrm{~m}$ within the forest than it was at any of the edge or field interior locations (Tukey's HSD test, $\alpha=0.05$ ) (Fig. 3). Mean DIN $4 \mathrm{~m}$ within the forest $\left(0.090 \pm 0.051\right.$ infected nymphs $\left./ \mathrm{m}^{2}\right)$ was more than four times higher than it was at 1 or $11 \mathrm{~m}$ into the field, and more than 36 times higher than it was at 21 or $34 \mathrm{~m}$ into the field (Table 1). On the forest side of the edge, DIN was not a function of distance from forest edge $\left(R^{2}=0.03, P=0.36, n=\right.$ $34)$; however, the difference in DIN between the edge (0-10 $\mathrm{m})$ and interior $(20-50 \mathrm{~m})$ portions of the forest when the 


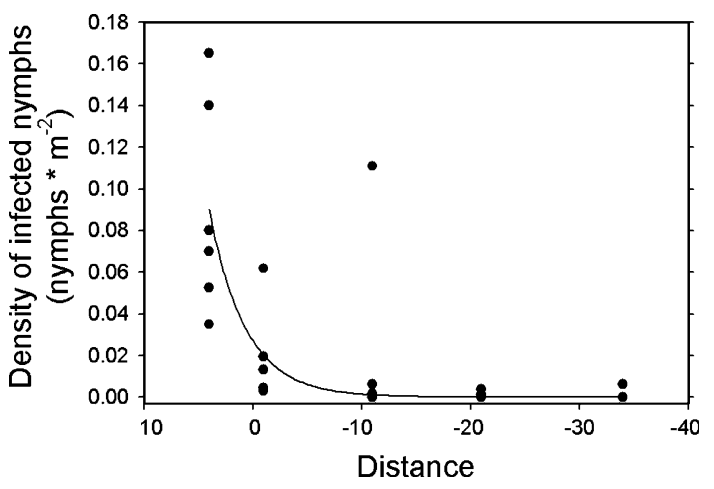

Figure 3. Density of infected nymphs (DIN) as a function of distance from forest edge into old fields, where forest distances are represented by positive values, the edge by zero, and field distances by negative values (exponential decay curve, $R^{2}=0.53, P<0.0005, N$ $=30$ ).

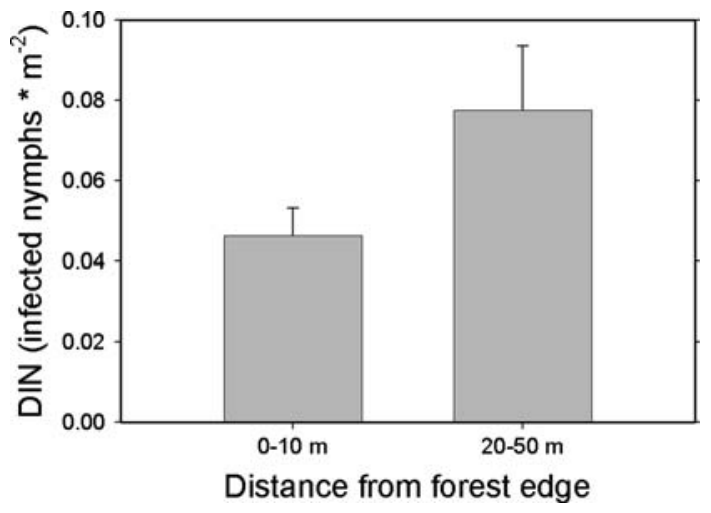

Figure 4. Mean density of infected nymphs (DIN) \pm 1 SE for forest edge $(0-10 \mathrm{~m})$ vs. forest interior $(20-50 \mathrm{~m})$ transects $\left(\mathrm{t}_{\text {unequal }}=\right.$ $-1.79, P=0.08, n=34)$.

transects were grouped did approach significance $\left(\mathrm{t}_{\text {unequal }}=\right.$ $-1.79, P=0.08, n=34$ ) (Fig. 4). Within the interior portion, mean DIN averaged $0.077 \pm 0.016$ nymphs $/ \mathrm{m}^{2}$, compared to $0.046 \pm 0.007$ nymphs $/ \mathrm{m}^{2}$ in the edge transects. For individual distance categories within the forest, mean DIN ranged from $0.033 \pm 0.009$ to $0.094 \pm 0.042$ infected nymphs/ $\mathrm{m}^{2}$ (Table 2).

Finally, in examining the relationship between each of the measured microhabitat variables and the Lyme disease risk parameters, none of the three nymphal variables was a significant function of leaf litter depth nor downed wood abundance (All regressions, $P>0.05$ ).

\section{Discussion}

Our study of entomological risk of exposure to Lyme disease along a gradient from forest interior to adjacent her- baceous field interior revealed that densities of nymphal ticks and of infected nymphal ticks were considerably higher within forest than at forest-field edges, and were lowest within fields. The total density of nymphal Ixodes scapularis (DON) and the density of infected nymphs (DIN) increased substantially from the field interior (21-34 $\mathrm{m}$ from the forest edge) to the shallow forest $(4 \mathrm{~m}$ in) and again from the forest edge $(0-10 \mathrm{~m})$ to the forest interior (20-50 $\mathrm{m}$ in). Past studies have demonstrated dramatically increased nymphal abundance within forest habitat as compared to herbaceous habitats (e.g., Maupin et al., 1991; Stafford and Magnarelli, 1993; Duffy et al., 1994; Schmidtmann et al., 1994; Ostfeld et al., 1996). Higher abundances in forest than in fields have been interpreted as arising from more favorable abiotic conditions in the former (Maupin et al., 1991; Adler et al., 1992), although higher abundance of rodent hosts for larval ticks in forest (Morris, 1991; Markowski et al., 1998) also likely plays a role (Ostfeld et al., 1996). Tick abundance and infection prevalence at forest-herbaceous field edges have received much less attention.

Our results show clearly that forest-herbaceous field edges do not pose a higher entomological risk of exposure to $B$. burgdorferi than do the forests themselves, although risk at the edge is higher than in herbaceous habitat. The landscapes in Maryland associated with highest human incidence rates of Lyme disease were characterized by both high relative abundance of forest-herbaceous edge and intermediate levels (ca 53\%) of total forest cover (Jackson et al., 2006). Lyme disease incidence rates were low in landscapes consisting of a high percent cover of herbaceous habitat (Jackson et al., 2006). We suggest that all of these results are interpretable on the basis of our assessments of entomological risk. Given quite low densities of infected nymphal I. scapularis in herbaceous habitat described in our study, and repeatedly in other localities, we would expect that human incidence in landscapes characterized by herbaceous dominance will be low even if human use of these landscapes is high. On the other hand, landscapes dominated by forests might have low incidence despite high entomological risk if use of predominantly forested habitats by people is low. Landscapes with abundant edges between forested and herbaceous habitat and roughly even proportions of both would seem to attract both heavy human use and moderately high risk.

This interpretation of the causes of elevated incidence in edge-rich landscapes, if accurate, suggests complementary means of reducing Lyme disease incidence. On the one 
hand, educating local residents about the vastly greater risk of encountering an infected nymphal tick in forest compared to field or forest-field edge might stimulate the use of self-protective behaviors, including avoidance of forest, use of protective clothing, application of repellent, and conduct of "tick checks," particularly when forests are visited. On the other hand, these landscapes would seem to be ideal venues for the application of either biological or judicious chemical control measures aimed at ticks (Ostfeld et al., 2006). Biological and chemical control agents will likely be considerably more effective if applied to forest interiors than to fields or forest-field edges, where ticks are relatively scarce. Because of these consequences for mitigation strategies, future studies of Lyme disease exposure would benefit from explicit exploration of human versus entomological risk in focal habitats.

\section{CONCLUSIONS}

Edges between forest and herbaceous habitat recently have been associated with high Lyme disease incidence rates (Jackson et al., 2006), although underlying mechanisms are not well understood. Through field sampling of blacklegged ticks and laboratory testing for infection with Borrelia burgdorferi, we rejected one candidate mechanism-that density and infection prevalence of blacklegged tick vectors is higher at edges than in other landcover types. Tick densities were higher within forests than at edges, and lowest in herbaceous fields. Infection prevalence did not vary significantly along this gradient. We conclude that elevated risk associated with forest-field edges is likely a consequence of human behavior rather than entomological parameters.

\section{ACKNOWLEDGMENTS}

The authors thank the National Science Foundation (REU program and Ecological Biology program) and the National Institutes of Health (NIAID) for funding this research. Ray Winchcombe and Kelly Oggenfuss provided crucial logistical support. This is a contribution to the program of the Institute of Ecosystem Studies.

\section{REFERENCES}

Adler GH, Telford SR III, Wilson ML, Spielman A (1992) Vegetation structure influences the burden of immature Ixodes dammini on its main host, Peromyscus leucopus. Parasitology 105:105-110
Barbour AG, Fish D (1993) The biological and social phenomenon of Lyme disease. Science 260:1610-1616

Cadenasso ML, Traynor MM, Pickett STA (1997) Functional location of forest edges: gradients of multiple physical factors. Canadian Journal of Forest Research 27:774-782

Centers for Disease Control and Prevention (CDC) (2004) Lyme disease- United States, 2001-2002. MMWR. Morbidity and Mortality Weekly Report 53:365-369

Das A, Lele SR, Glass GE, Shields T, Patz J (2002) Modelling a discrete spatial response using generalized linear mixed models: application to Lyme disease vectors. International Journal of Geographical Information Science 16:151-166

Dinser R, Jendro MC, Schnarr S, Zeidler H (2005) Antibiotic treatment of Lyme borreliosis: what is the evidence? Annals of Rheumatic Diseases 64:519-523

Dister SW, Fish D, Bros SM, Frank HD, Wood BL (1997) Landscape characterization of peridomestic risk for Lyme disease using satellite imagery. American Journal of Tropical Medicine and Hygiene 57:687-692

Duffy DC, Clark DD, Campbell SR, Gurney S, Perello R, Simon N (1994) Landscape patterns of abundance of Ixodes scapularis (Acari, Ixodidae) on Shelter Island, New York. Journal of Medical Entomology 31:875-879

Falco RC, Fish D (1992) A comparison of methods for sampling the deer tick, Ixodes dammini, in a Lyme disease endemic area. Experimental and Applied Acarology 14:165-173

Frank DH, Fish D, Moy FH (1998) Landscape features associated with Lyme disease risk in a suburban residential environment. Landscape Ecology 13:27-36

Jackson LE, Hilborn ED, Thomas JC (2006) Towards landscape design guidelines for reducing Lyme disease risk. International Journal of Epidemiology 35:315-322

Markowski D, Ginsberg HS, Hyland KE, Hu R (1998) Reservoir competence of the meadow vole (Rodentia: Cricetidae) for the Lyme disease spirochete Borrelia burgdorferi. Journal of Medical Entomology 35:804-808

Mather TN (1993) The dynamics of spirochete transmission between ticks and vertebrates. In: Ecology and Environmental Management of Lyme Disease, Ginsberg HS (editor), New Brunswick, NJ: Rutgers University Press, pp 43-60

Maupin GO, Fish D, Zultowsky J, Campos EG, Piesman J (1991) Landscape ecology of Lyme disease in a residential area of Westchester County, New York. American Journal of Epidemiology 133:1105-1113

Morris DW (1991) Fitness and patch selection by white-footed mice. The American Naturalist 138:702-716

Murcia C (1995) Edge effects in fragmented forests: implications for conservation. Tree 10:58-62

Orloski KA, Hayes EB, Campbell GL, Dennis DT (2000) Surveillance for Lyme disease-United States, 1992-1998. MMWR. Morbidity and Mortality Weekly Report 49(SS03):111

Ostfeld RS, Hazler KR, Cepeda OM (1996) Temporal and spatial dynamics of Ixodes scapularis (Acari: Ixodidae) in a rural landscape. Journal of Medical Entomology 33:90-95

Ostfeld RS, Keesing F (2000) The function of biodiversity in the ecology of vector-borne zoonotic diseases. Canadian Journal of Zoology 78:2061-2078

Ostfeld RS, Price A, Hornbostel V, Benjamin M, Keesing F (2006) Controlling ticks and tick-borne zoonoses with biological and chemical agents. BioScience 56:383-394 
Piesman J, Mather TN, Dammin GJ, Telford SR III, Lastavica CC, Spielman A (1987) Seasonal variation of transmission risk of Lyme disease and human babesiosis. American Journal of Epidemiology 126:1187-1189

Schmidtmann ET, Carroll JF, Potts WJE (1994) Host-seeking of blacklegged tick (Acari: Ixodidae) nymphs and adults at the woods-pasture interface. Journal of Medical Entomology 31:291296
Stafford KC, Magnarelli LA (1993) Spatial and temporal patterns of Ixodes scapularis (Acari, Ixodidae) in Southeastern Connecticut. Journal of Medical Entomology 30:762-771

Van Buskirk J, Ostfeld RS (1998) Habitat heterogeneity, dispersal, and local risk of exposure to Lyme disease. Ecological Applications 8:365-378

Williams-Linera G (1990) Vegetation structure and environmental conditions of forest edges in Panama. Journal of Ecology 78:356-373 